\title{
Morphology and Electrophysiological Properties of Reticularis Thalami Neurons in Cat: In Vivo Study of a Thalamic Pacemaker
}

\author{
Christophe Mulle, ${ }^{1}$ Anamaria Madariaga, and Martin Deschênes \\ Laboratoire de Neurophysiologie, Département de Physiologie, Faculté de Médecine, Université Laval, Québec \\ G1K 7P4, Canada
}

Reticularis thalami neurons (RE neurons) were identified morphologically, and their electrophysiological properties were studied in cat under barbiturate anesthesia. Intracellular HRP injections showed that RE neurons possessed very long dendrites bearing numerous filopodia-like appendages and that their axons were directed toward main thalamic nuclei. As a rule, small axonal branches were also emitted within the RE nucleus itself. At rest, the membrane potential of RE neurons displayed 2 types of oscillations: a slow $0.1-0.2 \mathrm{~Hz}$ oscillation and fast 7$12 \mathrm{~Hz}$ oscillations occurring on the positive phase of the former. Episodes of spindle (7-12 Hz) waves lasted for 2-3 sec and were characterized by rhythmic depolarizations and burst discharges. Intracellular injections of QX314 and current pulse analyses revealed the presence in $\mathrm{RE}$ cells of 2 distinct inward currents: a persistent current that promoted tonic firing and a low-threshold current deinactivated by hyperpolarization that generated burst discharges. The low-threshold current deinactivated with large somatic hyperpolarizations (up to $30 \mathrm{mV}$ ) and produced depolarizing responses that lasted for about $70 \mathrm{msec}$. In addition, low-threshold responses appeared rhythmically at intervals of about $150 \mathrm{msec}$ after recovery of the membrane potential from hyperpolarization. Because of their duration, voltage dependence, and persistence after intracellular injections of QX314, it is suggested that these responses resulted from activation of a low-threshold $\mathrm{Ca}^{2+}$ current at the dendritic level. In QX314injected cells, selective components of spontaneous oscillations were abolished, among them the positive phase of the slow oscillation and late depolarizing humps that followed burst discharges within spindle sequences. However, the rhythmic occurrence of spindle episodes at $0.1-0.2 \mathrm{~Hz}$ was never affected by $\mathrm{DC}$ currents or by $\mathrm{QX314}$ or $\mathrm{Cl}^{-}$injections, suggesting that oscillations within a particular RE neuron partly reflected the oscillatory behavior of a network of cells. On the basis of these electrophysiological results and the known morphological and neurochemical features, a new hypothesis is proposed to account for the rhythmicity of RE neurons.

Received Feb. 21, 1985; revised Jan. 31, 1986; accepted Feb. 17, 1986

We thank our colleagues Dr. M. Steriade, G. Oakson, and L. Domich for helpful discussions over the last 2 years. We also thank $M$. Cardinal, P. Giguère, and D. Drolet for their technical and clerical assistance. This work was supported by the Canadian Medical Research Council Grant MT-5877. M. Deschênes is a scholar from Le Fonds de la Recherche en Santé du Québec. C. Mulle was a fellow on leave from Institut Pasteur, Paris. We are pleased to acknowledge Dr. A. Padjen of McGill University for the gift of QX314.

Correspondence should be addressed to Dr. Martin Deschênes at the above address.

' Present address: Laboratoire de Neurobiologie Moléculaire, Institut Pasteur, Paris, France.

Copyright (c) 1986 Society for Neuroscience $0270-6474 / 86 / 082134-12 \$ 02.00 / 0$
The origin of cortical spindle waves has long been a matter of great interest in neurophysiology because these high-voltage EEG oscillations are associated with behavioral states of decreased alertness (drowsiness and sleep). In the 1940s, it was shown that spindles originated in the thalamus (Morison and Basset, 1945), and this has been repeatedly confirmed (Andersson and Manson, 1971; Deschênes et al., 1984; Velasco et al., 1968; Villablanca and Schlag, 1968). On the basis of EEG recordings obtained after stimulation of various thalamic nuclei, Dempsey and Morison (1942) proposed that spindles originated in intralaminar thalamic nuclei. This conclusion was also reached by Jasper (1954), who included the reticularis (RE) thalami nucleus in the group of pacemaker nuclei. Later experiments by Andersen et al. (1967) showed that spindle oscillations persisted in lateral thalamic nuclei after destruction of the intralaminar and midline thalamus. It was then concluded that all thalamic nuclei possessed an equal propensity for spindling; this led to the "facultative pacemaker theory" (Andersen and Andersson, 1968), which emphasized the role of intrinsic membrane properties (the so-called postanodal exaltation phenomenon) and intrathalamic inhibitory feedback connections in the genesis of spindles. Then, for about a decade, research in this field virtually ceased. Meanwhile, the advent of new anatomical and electrophysiological techniques has changed our conceptual framework, and this has necessitated a new appraisal of this important problem.

Recently, 2 series of papers dealt with the electrophysiological properties of thalamic neurons (Deschênes et al., 1984; Jahnsen and Llinás, 1984a, b; Roy et al., 1984). These intracellular investigations were conducted in vivo in cats and in guinea pig thalamic slices in vitro. On one hand, it has been shown in vitro that thalamic neurons possess a set of intrinsic membrane properties that could underlie spindle oscillations. On the other hand, in vivo experimentations showed that IPSPs are the main phasing events of membrane potential oscillations in thalamocortical neurons, and it was concluded that some pool of inhibitory cells within the thalamus controls the genesis of spindles. This conclusion was later supported by experiments showing that spindle oscillations were abolished in thalamocortical neurons by transections or kainic acid injections that deprived them of their RE input (Steriade et al., 1985). More importantly, it was also observed that oscillations persisted in the rostral pole of the RE nucleus after transections that completely isolated this region from the rest of the thalamus (Steriade et al., in press). It was then proposed that the RE nuclear complex was the pacemaker structure of thalamic spindle oscillations.

It is known that cat and monkey RE neurons possess histological, anatomical, and neurochemical features different from those of other thalamic neurons (see review by Steriade and Deschênes, 1984), and one may wonder if these cells do not also 

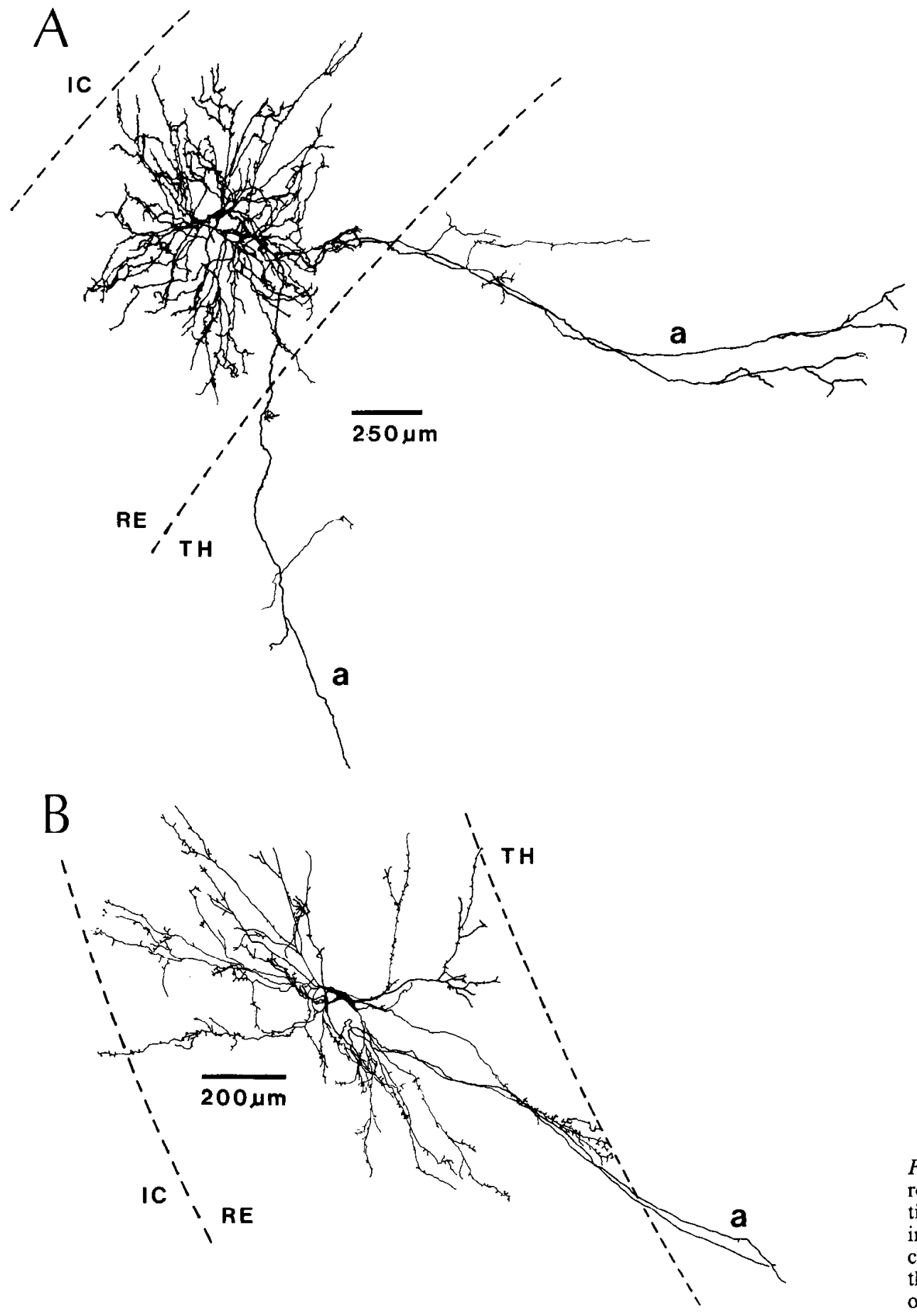

Figure 1. Morphology of 2 RE neurons revealed by intracellular injections of HRP. Both cells were located in the rostrolateral pole of the RE nucleus. $R E$, Reticularis nucleus; $T H$ thalamus; $I C$, internal capsule; $a$, axonal branches.

possess intrinsic membrane properties that could allow them to act as pacemakers of thalamic oscillations.

\section{Material and Methods}

\section{Electrophysiology}

Experiments were conducted on adult cats under Na-pentobarbital anesthesia $(35 \mathrm{mg} / \mathrm{kg})$. Cats were paralyzed with gallamine triethiodide, and their internal temperature was kept between 37 and $39^{\circ} \mathrm{C}$. Stimulating electrodes were implanted in the pericruciate area and brachium conjunctivum. After removal of the cortex over the head of the caudate nucleus and rostral thalamus, micropipettes were directed toward the rostral RE complex at a rostrocaudal angle of $25^{\circ}$. Stable recordings were obtained by cisternal drainage and bilateral pneumothorax. Mi- cropipettes were filled with various electrolytes (in $\mathrm{M}$ ) as follows: $3 \mathrm{~K}$ acetate, $2 \mathrm{~K}$ acetate plus $1 \mathrm{KCl}, 3 \mathrm{~K}$ acetate plus $0.1 \mathrm{QX} 314$. Their DC resistance ranged between 30 and $45 \mathrm{M} \Omega$. Data were recorded on a 4-channel tape recorder with FM electronics having a $0-5 \mathrm{kHz}$ bandwidth and on a Brush polygraph. Data analysis was made with a digitizing waveform analyzer (Data 6000, Analogic) and by conventional photographic methods. In some cases, chart recordings of rapid transients were made by reducing the tape recorder speed in the playback mode. In this way, membrane potential events below $125 \mathrm{~Hz}$ could be fully reproduced, but action potentials remained largely attenuated.

\section{Morphology}

In 12 cats, RE neurons were injected intracellularly with HRP in order to correlate electrophysiological features with unequivocal morpholog- 


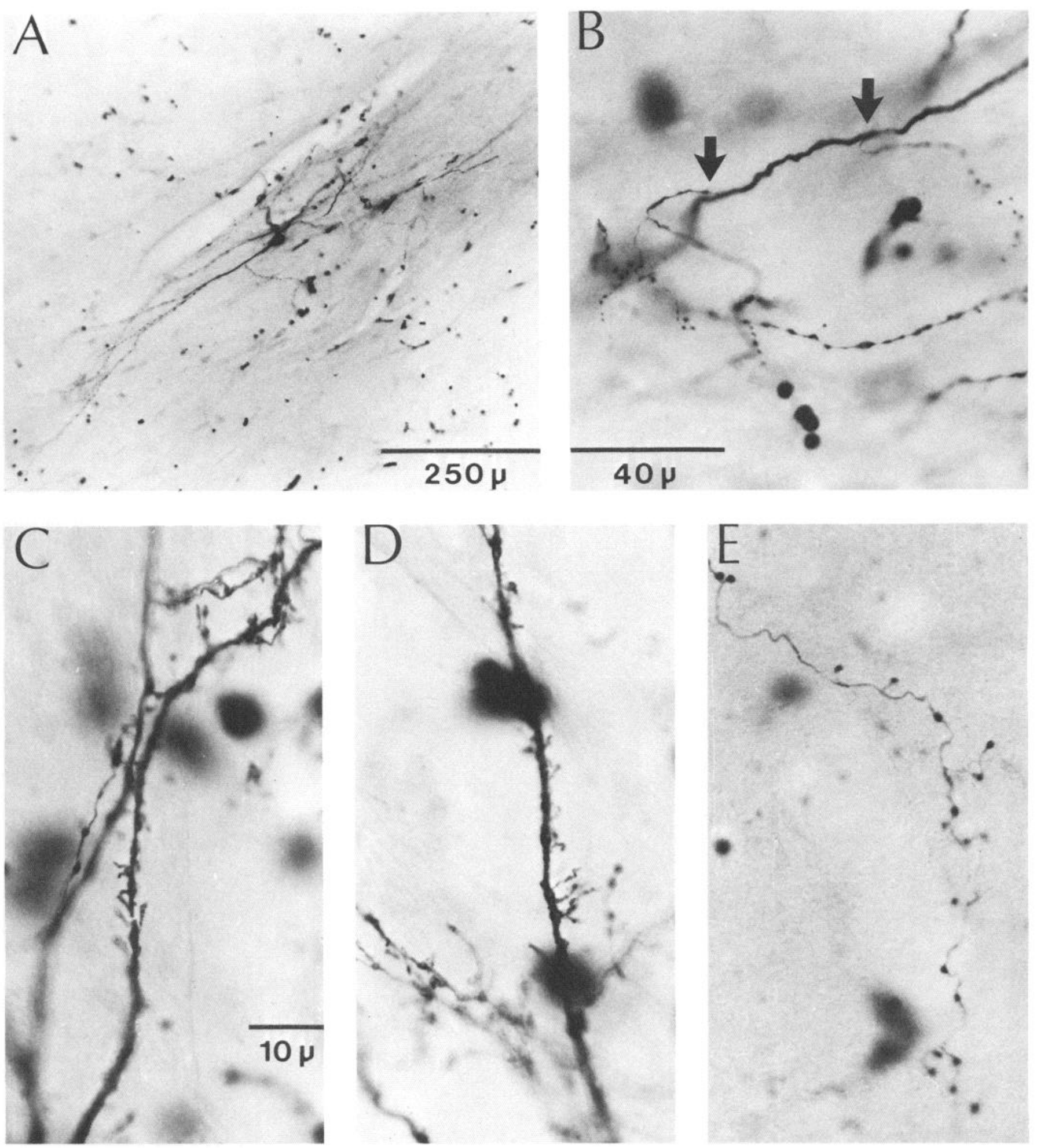

Figure 2. Photomicrographs of RE neuron processes after intracellular injections with HRP. $A$, Low-power view of a RE cell soma and dendrites located in the rostrolateral pole of the RE nucleus. $B$, Two collaterals (arrows) issued from a RE cell axon within the RE nucleus. $C$ and $D$, Highpower views of appendages on RE cell dendrites. $E$, Endings of a RE cell axon within main thalamic nuclei.

ical identification. Intracellular iontophoresis was performed with pipettes filled with a solution of 4\% HRP (4\% HRP Boehringer Grad I plus $0.5 \mathrm{M} \mathrm{K}$ acetate dissolved in a $0.05 \mathrm{M}$ Tris solution, $\mathrm{pH} 7.6$ ). Within $2 \mathrm{hr}$ after a successful injection, perfusion was carried out with a mixed aldehyde solution $(0.8 \%$ paraformaldehyde plus $2 \%$ glutaraldehyde in phosphate buffer, $\mathrm{pH} 7.4)$. Horizontal sections were cut at $80 \mu \mathrm{m}$ on a freezing microtome and reacted with diaminobenzidine according to previously described procedures (Landry and Deschênes, 1981). It was found important to carry out perfusion soon after injections, as long survival periods resulted in clear signs of degeneration in labeled neurons (dendrites became tortuous and beaded).

\section{Sample size and general comments}

Data selected for this report were obtained from 24 RE neurons recorded intracellularly under stable conditions (resting potentials of at least -50 
$\mathrm{mV}$ ) and from 10 additional RE neurons injected with HRP. They were all located in the rostral pole of the RE nucleus between frontal planes F.11 and F.13.

Stable cellular impalements of RE cells were particularly difficult to achieve. The relatively low density of neurons in the RE complex, together with its thinness, may partly account for this difficulty. In addition, the high content of myelinated fibers in this nucleus may also create unfavorable mechanical conditions for cellular impalement. Nevertheless, the uniformity of results yielded by stable recordings in different preparations provides enough background to support the conclusions reached in the present report.

\section{Results}

\section{Morphological characteristics of RE neurons}

Neurons located in the rostral, thicker part of the RE nuclear complex generated radiating dendrites with little obvious orientation (Fig. $1 A$ ). Those located more caudally (Fig. $1 B$ ), where the nucleus is thinner and more sheetlike, had dendrites showing a high degree of streaming, with shafts running parallel to the curved axis of the nucleus. The total extent of dendritic territories could reach $1-1.2 \mathrm{~mm}$. Somata were usually elongated and had diameters of about $25 \times 45 \mu \mathrm{m}$. In $60 \%$ of injected cells, short stubby spines were observed on somata. RE neurons had 5-6 primary dendrites $2-4 \mu \mathrm{m}$ in diameter that gave rise to 3-4 secondary branches within $100 \mu \mathrm{m}$ of leaving the soma. As a rule, these secondary branches were generated within a very short dendritic space, giving the impression that they all diverge from a common branch point. Along their course, secondary dendrites gave small-sized branches, which were densely covered with long filamentous appendages (Fig. 2, $C, D$ ) crowned by small nodules. These filamentous processes could reach 15 $\mu \mathrm{m}$ in length.

RE cell axons had diameters of $2.0-3.0 \mu \mathrm{m}$ at their origin, and they all gave a small collateral branch that distributed within the dendritic domain of the parent cell (Fig. $2 B$ ). Within the RE nucleus itself, the main axon divided in 2 or 3 branches of roughly equal size $(1.5-2.0 \mu \mathrm{m})$ that ran caudally and medially within the main thalamic nuclei (Fig. 1). In most cases, the axonal path was lost before terminal branches could be visualized. In 2 cases, small collateral branches bearing terminals (Fig. $2 E$ ) were seen ramifying in thalamic nuclei. Yet no firm statement can be made concerning the spatial distribution of $\mathrm{RE}$ axonal terminals in the thalamus.

\section{Electrophysiological properties of $R E$ neurons}

\section{Spontaneous membrane potential oscillations}

When sampled intracellularly, RE cells fired rhythmic spike bursts similar to those recorded extracellularly. This is shown in Figure 3 for the same unit recorded before and after impalement. It is reasonable to conclude that stable impalements did not modify the normal behavior of these cells.

At rest, under conditions of barbiturate anesthesia, the membrane potential of RE neurons oscillated continuously. Two basic rhythms were observed. First, a slow rhythm of $0.1-0.2$ $\mathrm{Hz}$, characterized by periodic recurrence of a slowly growing and decaying depolarization (Fig. $4 A$ ), was noted. The positive phase of this oscillation was associated with the occurrence of phasic depolarizing events that led to burst discharges. The negative phase developed gradually and smoothly, returning the membrane potential to between -65 and $-70 \mathrm{mV}$. In no instance were phasic hyperpolarizations resembling IPSPs associated with the repolarizing phase. We refer to this rhythm as the slow rhythm or oscillation.

The second rhythm had a frequency of $7-12 \mathrm{~Hz}$ and was characterized by the periodic recurrence of shorter duration depolarizations ( $80 \mathrm{msec}$ ) and burst discharges that were related in time with the positive phase of the slow oscillation (Fig. $4 B$ ).
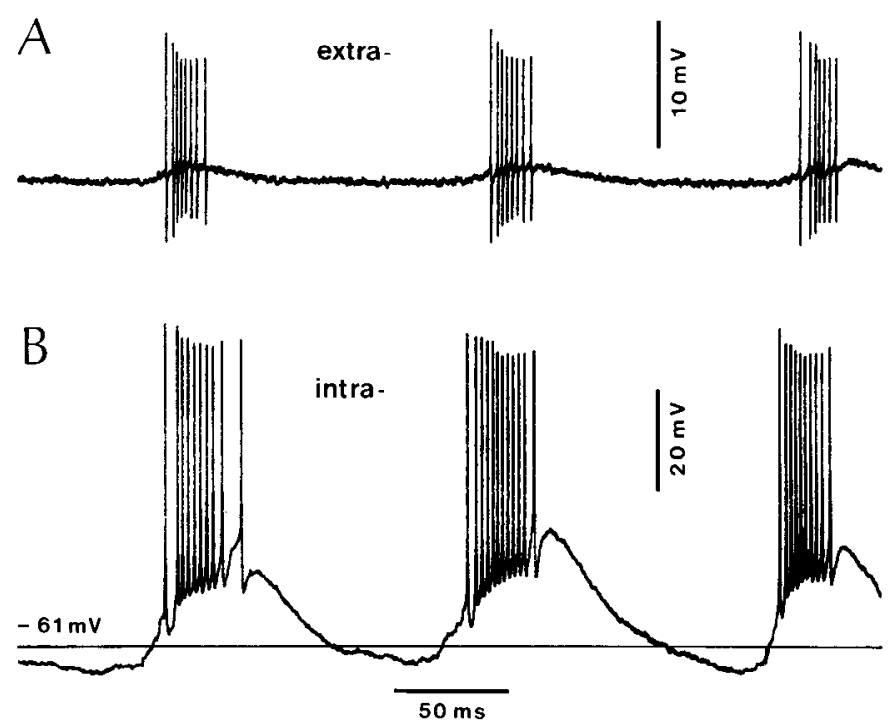

Figure 3. Episodes of rhythmic burst discharges recorded extracellularly $(A)$ and then intracellularly $(B)$ from the same RE neuron. Positivity up in trace $A$. In this and following figures, membrane potential values $(-61 \mathrm{mV})$ refer to baseline levels.

This faster rhythm corresponds to that of extracellularly recorded spindle waves, and hereafter we refer to it as the fast rhythm or spindle oscillation. Although the slow and fast rhythms always developed in phase, the former could be differentiated from the lattcr. As will be shown below, different mechanisms underlie both types of oscillations.

\section{Components of spindle oscillations}

Individual depolarizing waves that waxed and waned during spindle oscillations lasted for 75-100 mscc. At the beginning of spindle sequences they were somewhat shorter (i.e., $50 \mathrm{msec}$ ); the rising phase (see Fig. $5 \mathrm{~A}$, trace 1) consisted of a series of fast depolarizations followed by a slow and smooth decay phase. Later in the sequence, when depolarizations reached maximal amplitude and duration, additional components could be detected (Fig. $5 A$, trace 2). After an initial rising phase consisting of rapid depolarizations, a burst of 4-6 spikes was triggered, each of them having an increasing firing level (Fig. $5 \mathrm{~A}$, dashed line). Generally, spike frequency during bursts ranged from 150 to $350 \mathrm{~Hz}$. Finally, a late depolarizing hump occurred, and repolarization proceeded smoothly thereafter.

The nature and origin of fast-rising depolarizations are not yet clear. They may be EPSPs, dendritic active responses, or a mixture of both. What is most striking, however, is their occurrence in bursts having internal frequencies of $300-400 \mathrm{~Hz}$, that is, in the same frequency range as spike bursts fired by thalamocortical neurons during spindles. A typical spike burst recorded in a thalamocortical neuron is shown in Figure $5 B$, where the trace is aligned with traces of Figure $5 A$ in order to show the temporal relationship between spikes and fast-rising depolarizations. This close temporal relationship would suggest that fast-rising depolarizations were monosynaptic EPSPs produced by axonal collaterals of thalamocortical cells. This is also supported by the short latency and fast rise time of disynaptic EPSPs produced in this RE neuron by stimulation of brachium conjunctivum (Fig. 5C).

\section{Effect of hyperpolarizing currents on spindle oscillations}

Membrane hyperpolarization produced by sustained current injections did not modify the temporal pattern of the slow and fast rhythms. However, the amplitude of individual spindle waves was affected. As shown in Figure $6 B$, moderate hyper- 

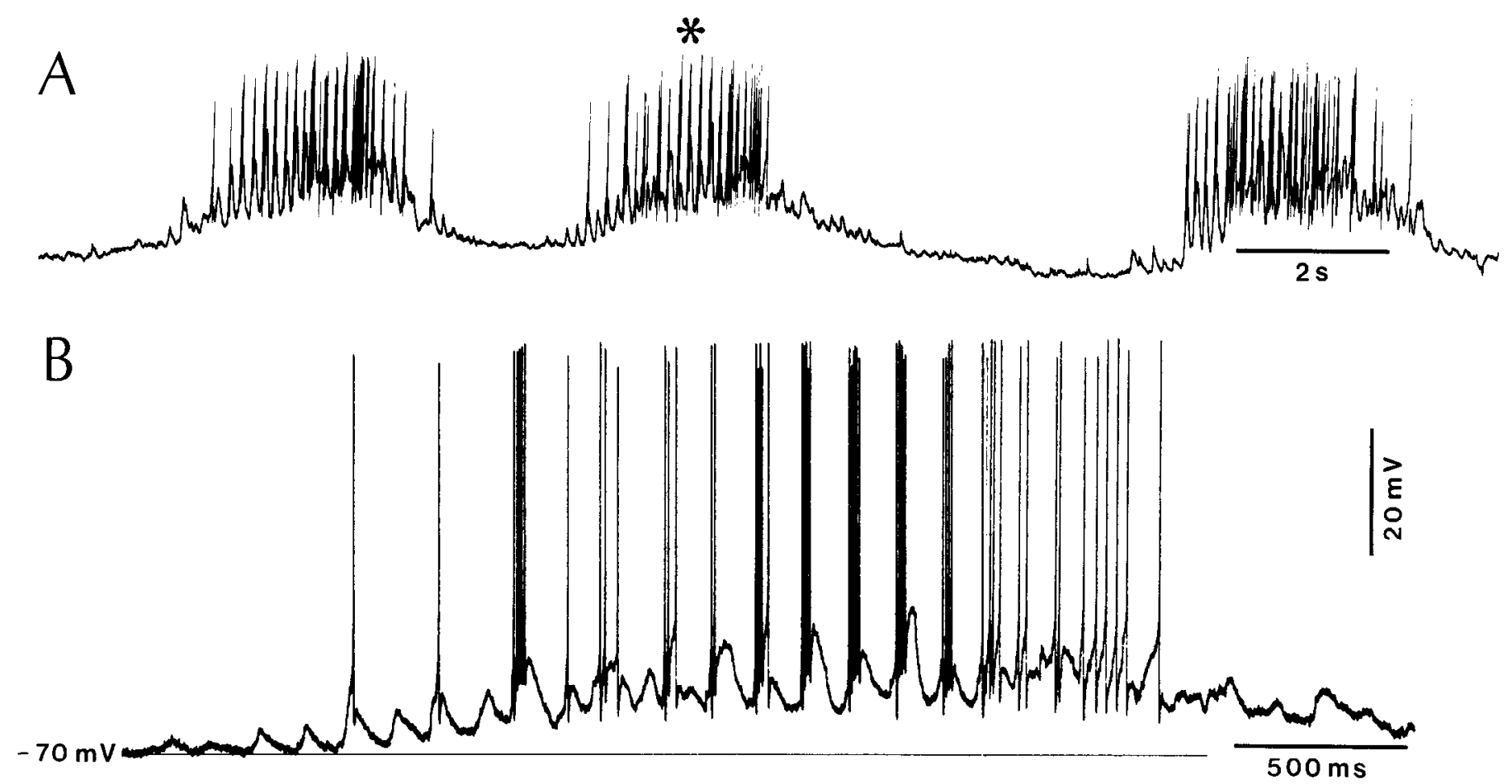

Figure 4. Spontaneous membrane potential oscillations of a RE neuron. Polygraphic recording in $A$ and oscilloscopic recording in $B$. Spindle sequence marked with an asterisk in $A$ is depicted in $B$.

polarizations blocked spike bursts and increased the amplitude of underlying depolarizations. Increasing the amount of steady inward current (Fig. 6C) decreased both the amplitude and duration of individual spindle waves. As a rule this was associated

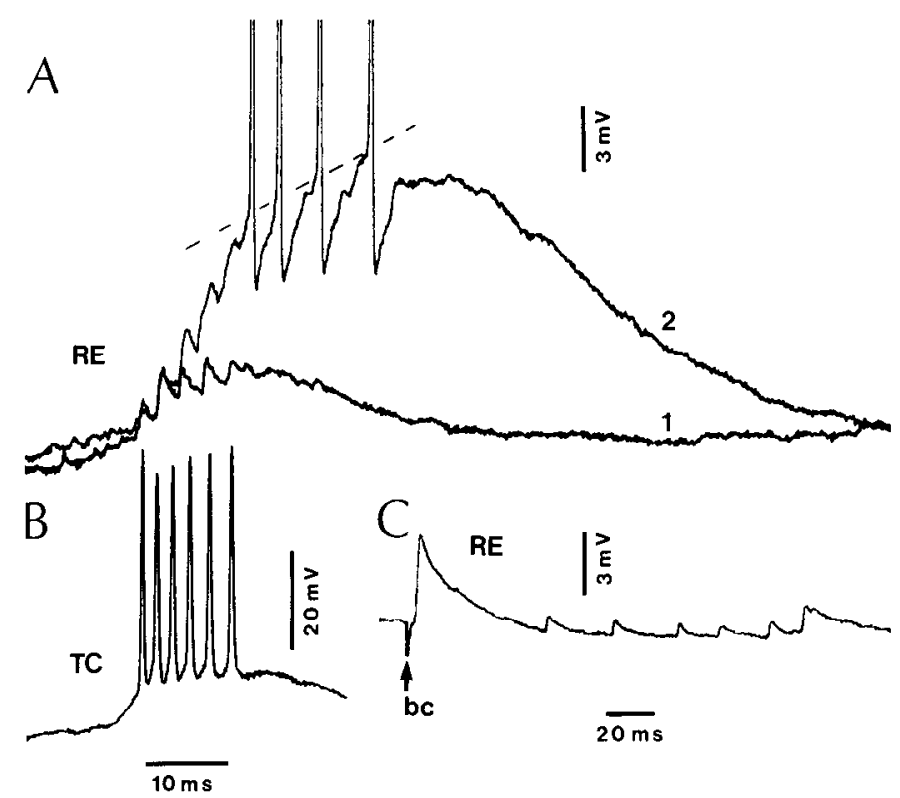

Figure 5. Fast-rising depolarizations associated with the occurrence of spindle oscillations in RE cells. $A$, Superimposed traces showing 2 portions of the same spindle sequence: trace 1 , beginning of the sequence; trace 2, middle of sequence. Note the increase of spike threshold (dashed line). B, Typical spike burst of a thalamocortical cell $(T C)$ is aligned with bursts of fast depolarizations of traces in $A$ to allow comparison of their internal frequencies. $C$, Transynaptic depolarization induced in the same RE neuron as in $A$ by stimulation of brachium conjunctivum $(b c)$. Resting potentials: $-66 \mathrm{mV}(A$ and $C)$ and $-58 \mathrm{mV}$ $(B)$. Same time base in $A$ and $B$. with a quasi all-or-none blockage of late-depolarizing humps. Attempts to modify the remaining wave pattern with larger inward currents were not successful.

\section{Cortically evoked responses in $R E$ neurons}

It has been shown that cortical stimulation induced spindlelike oscillations in thalamocortical neurons (Andersen et al., 1964; Roy et al., 1984; Steriade et al., 1972). In these cells, oscillations were made of long-lasting hyperpolarizations interrupted by occasional spike bursts. In RE neurons, cortical stimulation also induced similar oscillations, but of opposite polarity. Responses consisted of a series of depolarizing waves (Fig. $7 \mathrm{~A}$ ) and spike

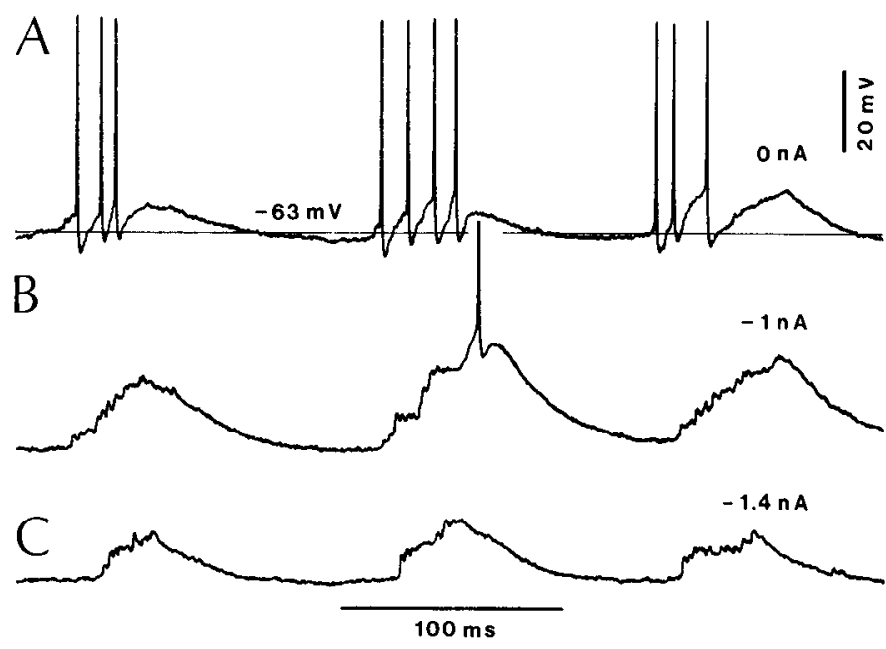

Figure 6. Effect of membrane hyperpolarization on spindle oscillations in RE neurons. $A$, No current; $B, 1$ nA hyperpolarizing current passed through the cell membrane. Note that the slow-wave component underlying burst discharges grew in size, but its amplitude and duration were reduced by additional inward current $(C)$. Spike amplitude truncated in $B$. 

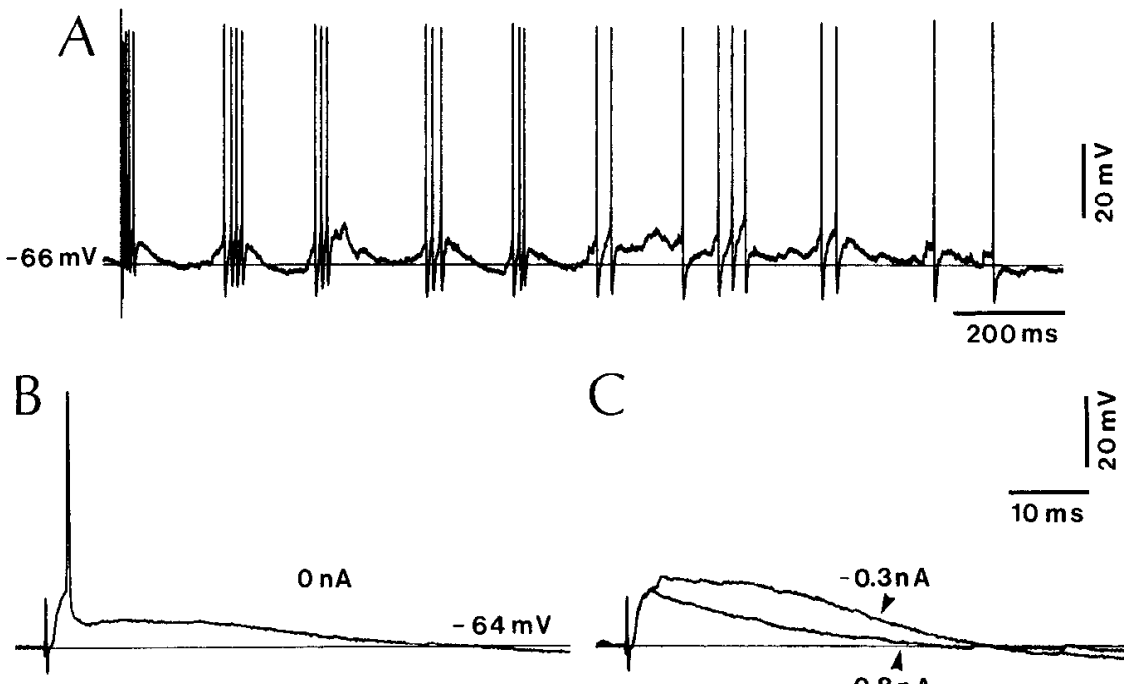

C

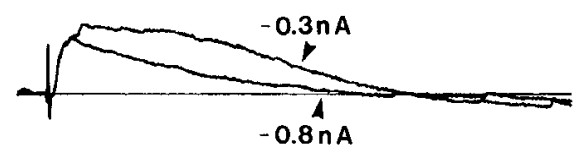

Figure 7. Response of RE neurons to cortical stimulation of variable intensities. $A$, Rhythmic oscillations and burst discharges triggered in RE neurons by cortical stimulation of maximal intensity. $B$, Early response to a cortical shock juxtathreshold for evoking a spike discharge. $C$, Effect of hyperpolarizing currents on the same response as in $B$. Note the increase in amplitude and then attenuation of the late phase of depolarization upon passing currents of increasing intensity. bursts fired at intervals of about $150 \mathrm{msec}$. Spike frequency within bursts (except for the first burst) ranged between 80 and $250 \mathrm{~Hz}$. In the early burst, firing could reach frequencies of up to $400 \mathrm{~Hz}$. This early burst in response to a cortical shock was the most reliable electrophysiological criterion for the identification of RE neurons.

At stimulus intensity subthreshold for inducing oscillations, the evoked response consisted of a short-latency $(0.6-1.0 \mathrm{msec})$ EPSP and spike discharge (Fig. $7 B$ ) followed by a prolonged depolarizing tail lasting $40 \mathrm{msec}$. Somatic hyperpolarization large enough to prevent spike discharges (Fig. $7 C$ ) revealed the prescnce of a rounded depolarizing wave that started at the peak at early EPSP. This late depolarization was blocked by further increasing membrane hyperpolarization, showing that an intrinsic voltage-dependent inward current was turned on by the preceding EPSP. This voltage-dependent component appears to be similar to the voltage-sensitive depolarizing hump that occurs during spindle oscillations (see Fig. 6C).

\section{Current-voltage relation in $R E$ neurons}

In order to study the intrinsic membrane properties of RE neurons, current pulses were injected into these cells. However, in doing so, one must take into account that, at rest, the membrane potential of RE neurons continually oscillates. The results pre- sented here were selected from recordings obtained during the negative quiescent phase of the slow oscillation. During interspindle lulls the membrane potential of RE cells reached resting values of -63 to $-70 \mathrm{mV}$, and input resistance measured in 12 neurons, by injecting small-amplitude current pulses (up to $0.5 \mathrm{nA}$ ) ranged between 12 and $20 \mathrm{M} \Omega$. Larger current injections revealed nonlinear membrane properties. This nonlinear behavior was best demonstrated by ramp current injections. In the example shown in Figure 8, the cell was held near $-80 \mathrm{mV}$ (resting potential, $-63 \mathrm{mV}$ ) by a steady hyperpolarizing current. The membrane potential was then depolarized to firing level by a ramp current rising linearly at approximately $12 \mathrm{nA} / \mathrm{sec}$. Around the resting level (between -58 and $-70 \mathrm{mV}$ ), the $I-V$ relation was almost linear, giving a mean input resistance of 14 $\mathrm{M} \Omega$. At values negative to $-70 \mathrm{mV}$, anomalous rectification was observed. As firing level was approached, a clear potential upswing was produced; this was followed by a slower rising depolarization demonstrating delayed rectification (as extrapolated from the spike trigger level or the undershoot of afterspike hyperpolarizations). When depolarizing trapezoidal current pulses were injected on a background of hyperpolarization, a membrane potential upswing led and lagged, respectivcly, the rising and falling components of the current pulse, demonstrating that this behavior was not dependent on a preceding period of hyperpolarization (Fig. 10E, arrowheads).

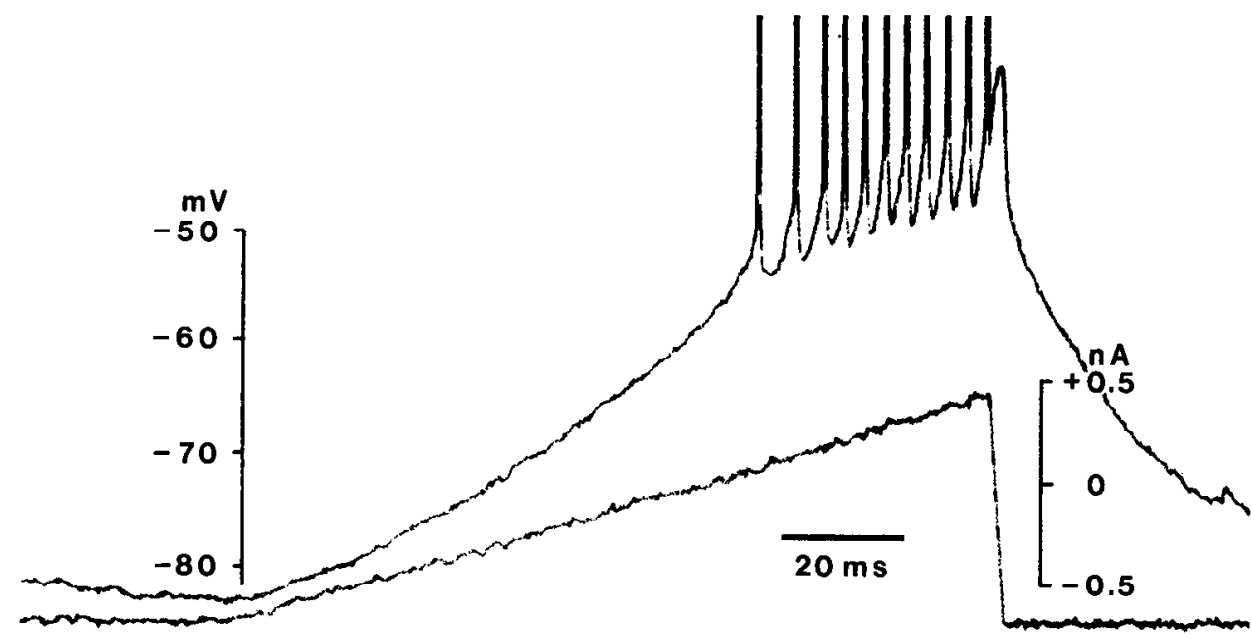

Figure 8. Current-voltage relation in RE neurons. A depolarizing ramp current was injected in a cell hyperpolarized by a sustained inward current. Note the membrane potential upswing preceding the first spike. Resting potential without current, -63 $\mathrm{mV}$. Spike amplitude truncated. 

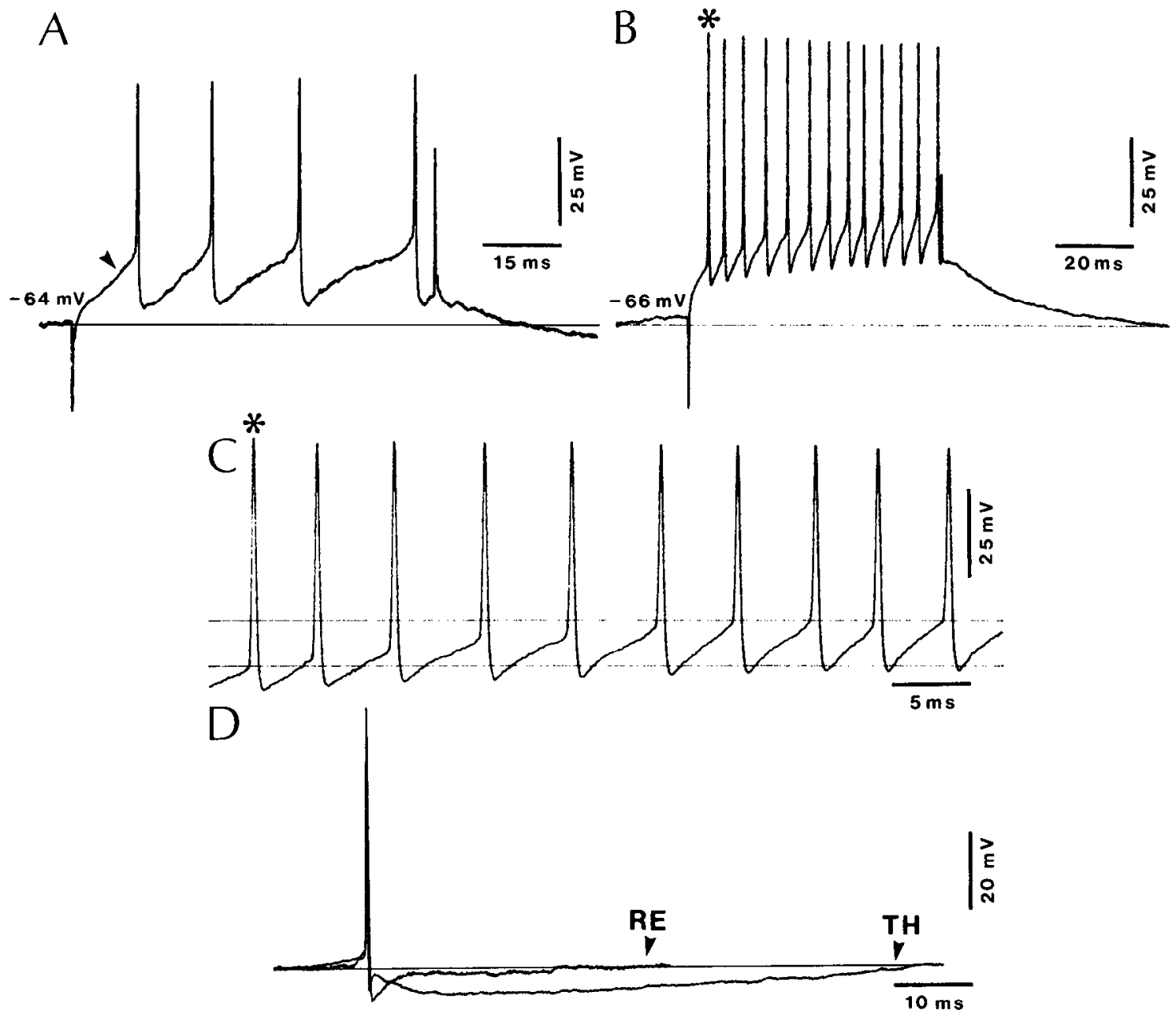

Figure 9. Spike triggering and AHPs in RE neurons. $A$, Slow ramplike voltage trajectory (arrowhead) preceding spike triggering in RE neurons. Current pulse intensity, $0.4 \mathrm{nA} . B$, Tonic firing in another RE cell induced by a depolarizing current pulse of $1 \mathrm{nA}$. $C$, Expansion of trace $B$. Asterisks in $B$ and $C$ point to the same spike in both traces. Note increase in spike threshold and the convex membrane potential trajectory between spikes in $C$. $D$, The AHP of the same RE cell as in $B$ is compared to that of a thalamocortical neuron (TH). Note the presence of a secondary AHP in the TH neuron. Resting potentials in $D:-60$ and $-62 \mathrm{mV}$ for RE and TH cells, respectively.

\section{Firing threshold and afterspike hyperpolarization (AHP) in $R E$ neurons}

Firing level in RE cells was reached through the activation of a ramplike depolarizing component (Fig. 9A, arrowhead). Strong depolarizing current pulses produced tonic spike discharges that were followed by a prolonged depolarizing tail after the break of the pulse (Fig. 9B). Tonic firing was always associated with a marked increase of the spike threshold. In the example shown in Figure $9 C$, the first spike (asterisk) was fired at $-50 \mathrm{mV}$, while the 10th spike reached threshold at $-38 \mathrm{mV}$. Spike accommodation reached $85 \%$ of its maximum after the 6 th action potential and then plateaued more slowly. It can also be noted that membrane potential trajectories between spikes changed from linear to convex as depolarization increased. This firing behavior was unique among thalamic neurons, as thalamocortical neurons never displayed such large accommodative changes.

Another distinctive difference between RE cells and thalamocortical neurons concerned the shape of after-hyperpolarizations (AHPs). For the sake of comparison, Figure $9 D$ shows isolated spikes of a RE cell and of a thalamocortical neuron that had equivalent resting potentials (within $3 \mathrm{mV}$ ) and spike amplitudes. In thalamocortical neurons, AHP was always biphasic and lasted for about $70 \mathrm{msec}$, while in RE neurons it was always monophasic and terminated after 8-10 msec. In most ncurons, it has been shown that the late AHP is mediated by a $\mathrm{Ca}^{2+}$ activated $\mathrm{K}^{+}$current (Meech, 1978). The absence of this component in RE cells could indicate that somatic spike electrogenesis was not accompanied by sizable $\mathrm{Ca}^{2+}$ entry or that $\mathrm{Ca}^{2+}$-activated $\mathrm{K}^{+}$currents were masked by dominant inward currents.

\section{Tonic versus burst firing in $R E$ neurons}

Depolarizing current pulses from rest $(-55$ to $-65 \mathrm{mV})$ produced tonic regular firing in RE neurons (Fig. 10A). On a background of steady hyperpolarization $(-75 \mathrm{mV}$ in Fig. $10 B)$, the same current pulses induced firing with a slower onset followed by a transient discharge acceleration. Again slightly increasing the level of hyperpolarization (Fig. 10C) revealed a slow depolarizing component that was time related to the firing acceleration seen previously. This slow component outlasted the break of the pulse by about $40 \mathrm{msec}$. Upon injection of additional inward current (Fig. 10D), this depolarizing component disappeared and, at the break of the pulse, the membrane potential returned passively to the imposed level within $20 \mathrm{msec}$. The voltage-dependent firing acceleration was better seen with depolarizing trapezoidal current pulses injected in cells already hyperpolarized by a sustained inward current. In the example 

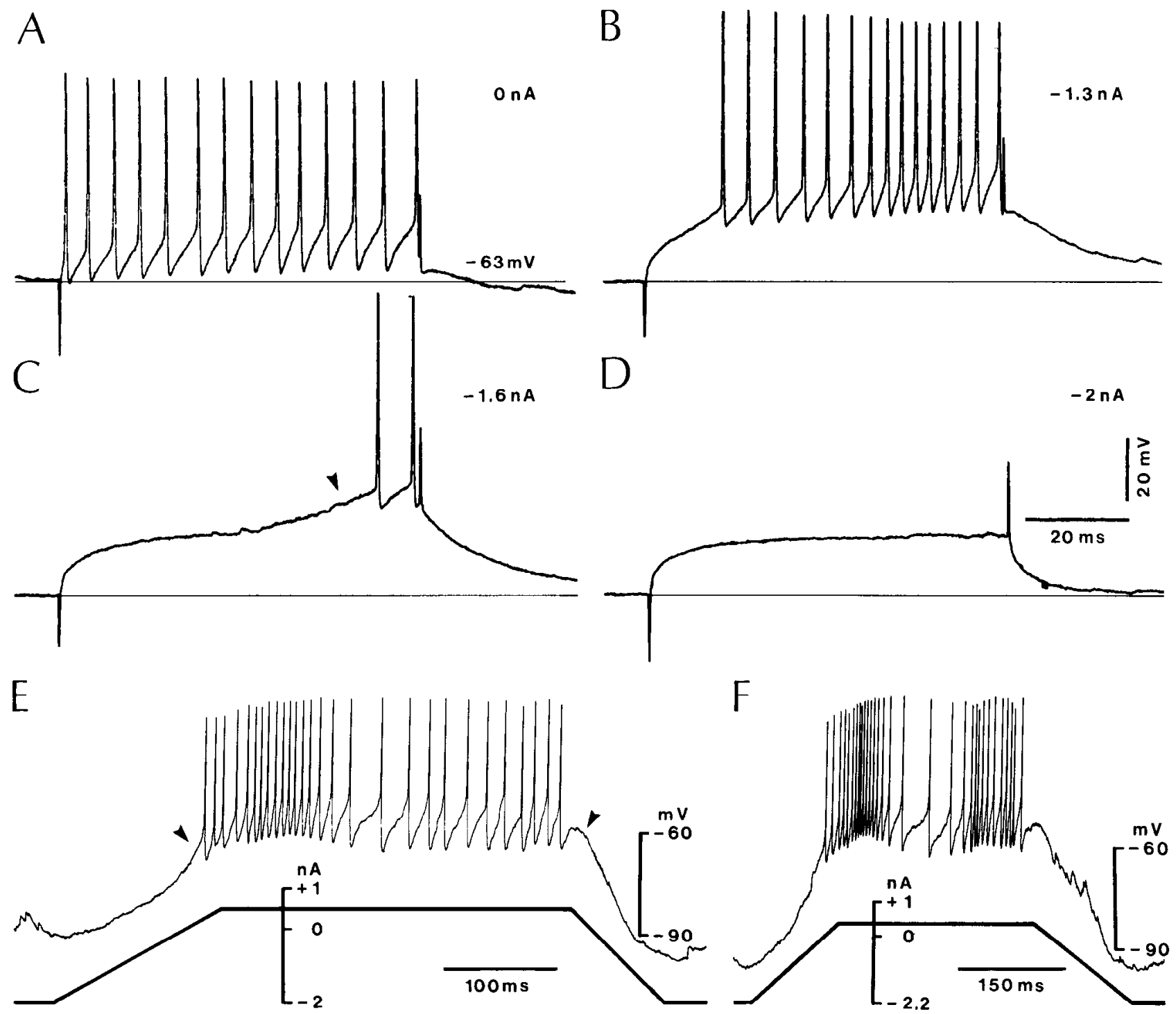

Figure 10. Modulation of discharge frequency by polarization of membrane potential in RE neurons. A depolarizing current pulse of 0.8 nA produced regular tonic firing at a resting potential of $-63 \mathrm{mV}(A)$. The same current pulse induced delayed regular firing followed by a transient acceleration of discharge frequency when delivered on a background of hyperpolarization $(B)$. A low-threshold voltage response underlying firing acceleration was isolated in $C$ (arrowhead), but it was no longer activated when the membrane potential was further hyperpolarized $(D)$. $E$ and $F$, Discharge frequency modulation in a RE neuron following injection of a trapezoidal current pulse on a background of hyperpolarization. Note upswing deflections (arrowheads) in $E$ and double burst discharges in $F$. Action potentials truncated in $E$ and $F$.

shown in Fig. 10E, the membrane potential was held at about $-90 \mathrm{mV}$ between pulses. After the fourth spike, discharge frequency increased for about $100 \mathrm{msec}$, although current intensity had already reached a steady level. This burst was followed by a frequency slowdown and a tendency to accelerate again. In many instances, double burst discharges were generated at intervals of 120 to $170 \mathrm{msec}$ (Fig. $10 F$ ).

The above results on spike firing mode suggest that 2 different voltage-dependent currents with overlapping operative ranges (as seen in the soma) control the firing mode of RE cells: First, a persistent inward current similar to the noninactivating $\mathrm{Na}^{+}$ current first described in Purkinje cells (Llinás and Sugimori, 1980); second, a transient inward current deinactivated by membrane hyperpolarization that underlies burst discharges. In order to dissociate both currents, attempts were made to block the presumed persistent $\mathrm{Na}^{+}$current by intracellular injections of QX314.
A QX314-resistant low-threshold inward current in RE cells After QX314 injections in RE neurons $(n=4)$, a depolarizing current pulse from rest no longer induced $\mathrm{Na}^{+}$spike discharges, but a slight progressive increase in membrane potential and a tail depolarizing response were still observed (Fig. 11A). When the same current pulse was delivered at a hyperpolarized potential level, a large low-threshold response (LTR) was triggered. In the example shown in Figure $11 B$, the LTR duration was probably contaminated by residual $\mathrm{Na}^{+}$currents due to the voltage dependence of QX314's blocking action (Puil and Carlen, 1984). This is indeed suggested by the triggering of abortive $\mathrm{Na}^{+}$spikes and by the presence of inflections in the LTR falling phase. A better estimate of the LTR time course was obtained by using short hyperpolarizing current pulses instead of steady inward currents. A 1 nA hyperpolarizing current pulse delivered from a resting level of $-58 \mathrm{mV}$ was followed by a rebound LTR 


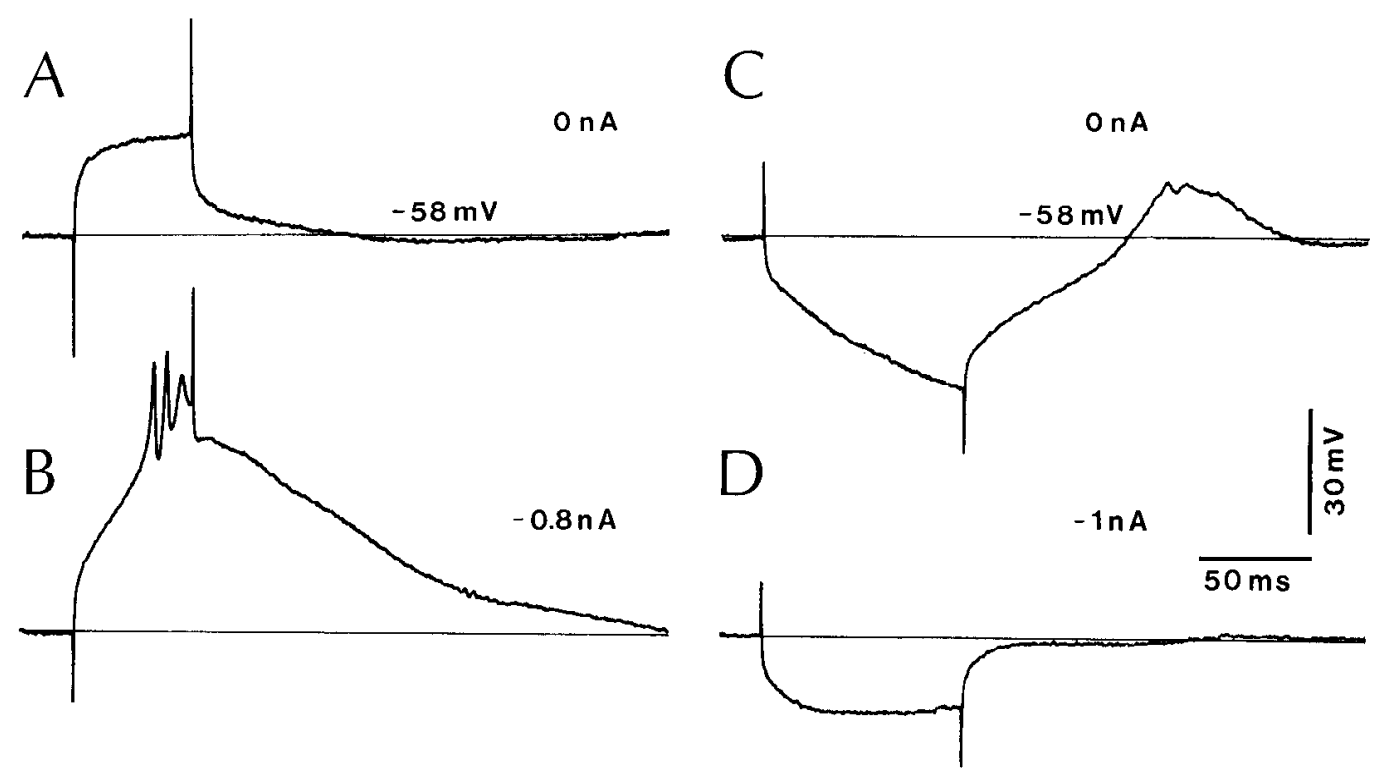

Figure 11. Deinactivation of a low-threshold inward current by membrane hyperpolarization of RE neurons after intracellular injection of QX 314 . $A$ and $B$, Depolarizing pulse of $1 \mathrm{nA}$ was injected while the membrane potential was hyperpolarized from its resting value of $-58 \mathrm{mV}(A)$ down to $-83 \mathrm{mV}(B) . C$ and $D$, Hyperpolarizing pulse of $1 \mathrm{nA}$ was injected at rest $(C)$ and while the membrane potential was kept close to $-90 \mathrm{mV}$ by a $1 \mathrm{nA}$ steady hyperpolarizing current $(D)$.

that lasted for about $75 \mathrm{msec}$ (Fig. 11C). When the membrane potential was held close to $-90 \mathrm{mV}$ by a steady inward current, the LTR did not occur (Fig. $11 D$ ) at the break of the pulse. This QX314-resistant, voltage-dependent LTR appears very similar to LTRs observed in the inferior olive (Llinás and Yarom, 1981)
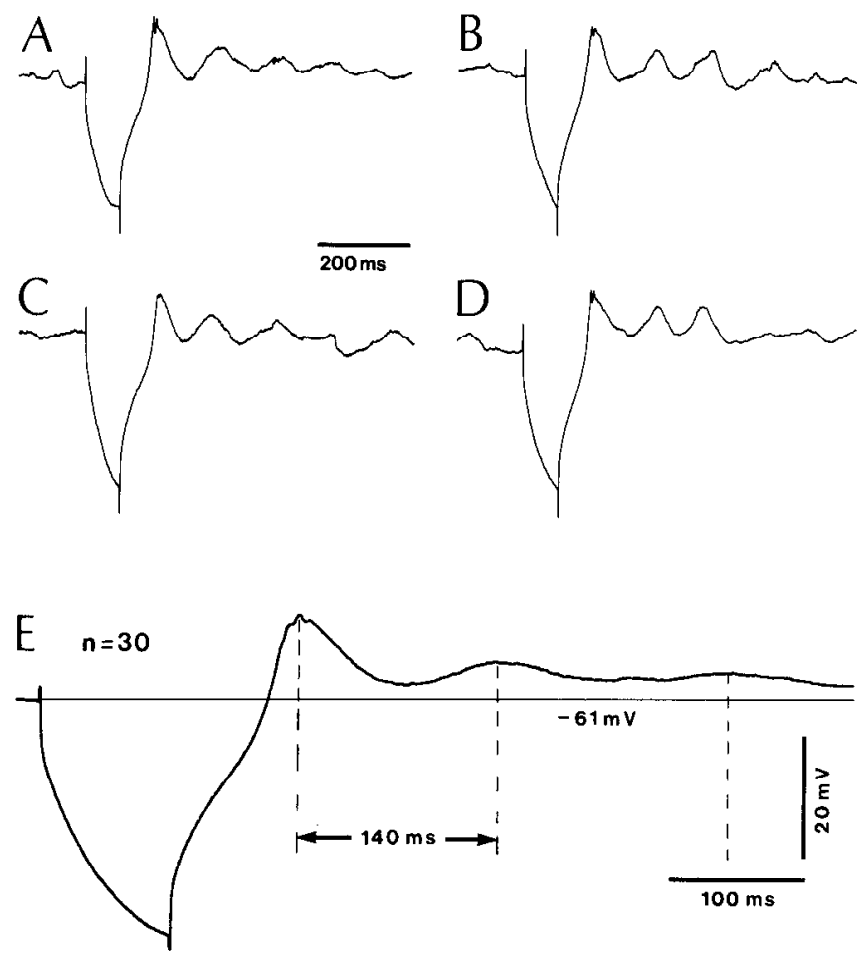

Figure 12. Oscillations triggered by current pulses in RE neurons after intracellular injection of QX314. Single sweep recordings in $A-D$ and averaging of 30 consecutive sweeps in $E$. Note the periodicity of about $140 \mathrm{msec}$ between peaks of rebound depolarizations. and thalamic neurons (Deschênes et al., 1984; Jahnsen and Llinás, $1984 \mathrm{a}, \mathrm{b}$ ). We presume, then, that it is a $\mathrm{Ca}^{2+}$-mediated response. However, RE cell LTRs were somewhat longer-lasting ( 75 vs $40 \mathrm{msec}$ in thalamic and inferior olive cells), and they always required larger somatic hyperpolarizations for deinactivation. In most cases, hyperpolarizations of $20-30 \mathrm{mV}$ from rest were necessary in RE neurons, while $5-10 \mathrm{mV}$ are usually effective in thalamic and inferior olive cells. These 2 features may indicate that low-threshold $\mathrm{Ca}^{2+}$ responses in $\mathrm{RE}$ neurons have a dendritic origin.

The most unexpected property of RE cell LTRs was their periodic recurrence after a single large hyperpolarizing pulse. In QX314-loaded neurons, large current pulses that drove the somatic membrane potential close to $-90 \mathrm{mV}$ produced rhythmic LTRs at intervals of about $140 \mathrm{msec}$ (Fig. 12). In single sweep traces (Fig. 12, $A-D$ ), 3-5 rhythmic responses followed current pulses. These oscillations were still present after averaging of 30 consecutive sweeps in spite of spontaneous fluctuations of membrane potential that might introduce slight phase shifts in the peak of postanodal responses (Fig. 12E). It must be noted that the second and third LTRs were not preceded by any apparent hyperpolarizing potentials.

\section{Outward currents activated by hyperpolarization in} RE neurons

As shown in Figures $11 C$ and 12 , the membranc potential of RE cells did not reach a steady level during hyperpolarizing current pulses but kept hyperpolarizing. This progressive increase in membrane potential could not be ascribed only to the cell time constant, since steady hyperpolarized levels were reached faster when current pulses were injected in a cell already hyperpolarized in the neighborhood of the $\mathrm{K}^{+}$equilibrium potential $(-90 \mathrm{mV}$ in Fig. $11 \mathrm{D})$. Activation of a yet unidentified voltage dependent outward current or gradual inactivation of an inward current might account for this rectification. Return to the original resting level after the break of the pulse also had a prolonged time course (Fig. $11 \mathrm{C}$ ). The mechanism of this slow return to baseline probably involved an early voltage-dependent $\mathrm{K}^{+}$conductance similar to that described as the A current by Connor and Stevens (1971). 

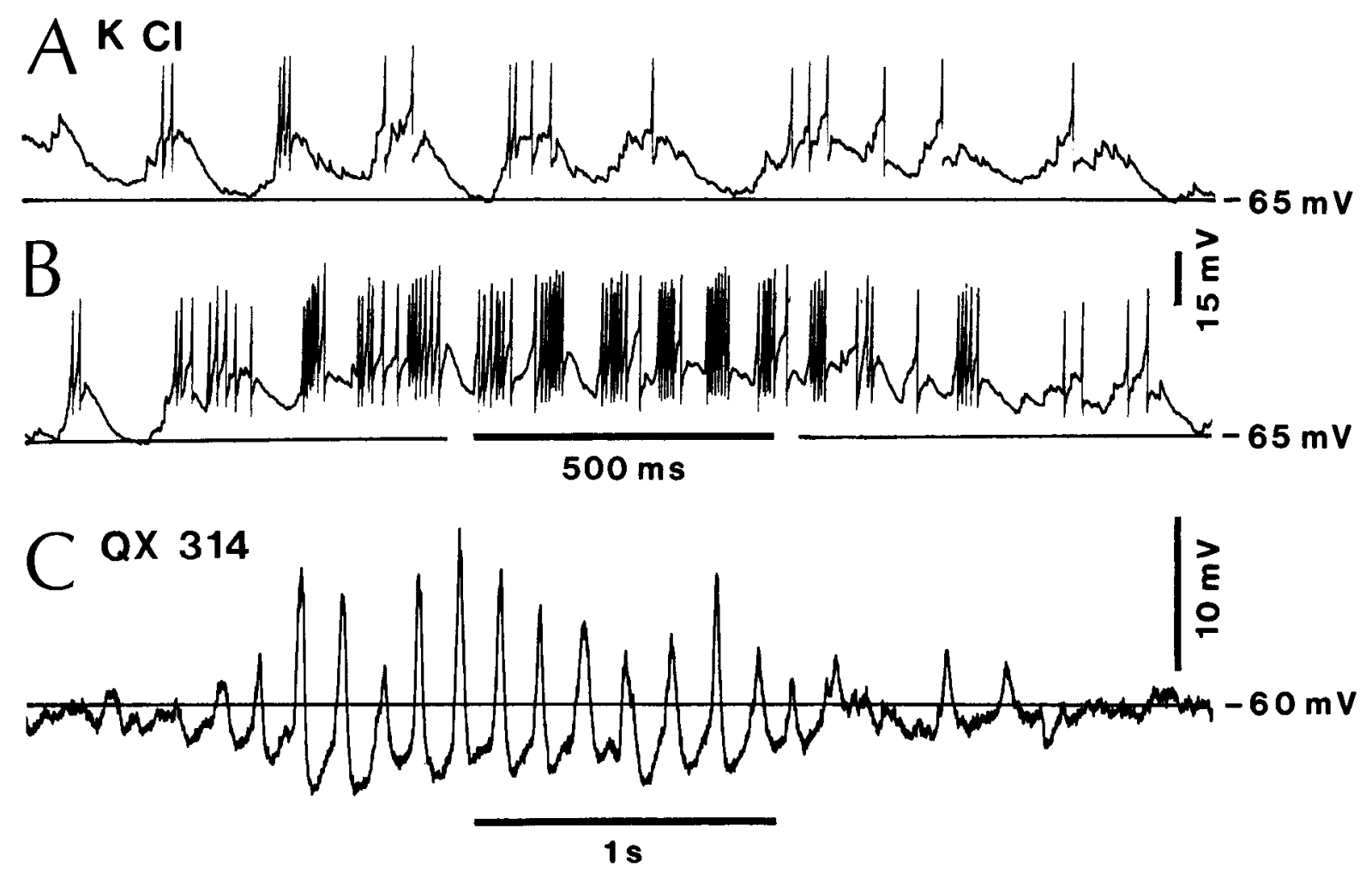

Figure 13. Effects of $\mathrm{Cl}^{-}$and QX314 injections on spontaneous spindle oscillations in RE neurons. Traces $A$ and $B$ are continuous. Recordings $A, B$, and $C$ were obtained from 2 different neurons.

\section{Effects of $Q X 314$ and $C l^{-}$injections on $R E$ cell oscillations}

The slow recurrence of spindle oscillations at $0.2-0.1 \mathrm{~Hz}$ was not modified by either QX314 or $\mathrm{Cl}^{-}$, even after prolonged periods of injection (up to $45 \mathrm{~min}$ ). However, these ions produced specific changes in the voltage and temporal characteristics of spindle oscillations.

Injections of QX314 produced a complete abolition of the slow depolarizing envelope associated with spindle sequences (Fig. 13C). Spindle oscillations developed as a series of hyperpolarizations followed by rebound depolarizing waves, the whole sequence being very similar to the oscillatory pattern of thalamocortical neurons. Within the spindle sequence itself, depolarizing events were always shorter lasting ( $50 \mathrm{vs} 80 \mathrm{msec}$ ) than in control recordings obtained with $\mathrm{K}^{+}$acetate-filled pipettes (Fig. 14, B, C). This shortening was mostly duc to the sclectivc disappearance of the late depolarizing humps within the sequence, an effect very similar to that produced by hyperpolarizing currents (see Fig. 6). It is then likely that these late depolarizing humps, as well as the slow depolarization, resulted from the activation of a voltage-dependent persistent $\mathrm{Na}^{+}$current.

Within 10 min after RE cell impalement with a $\mathrm{KCl}$-filled pipette, the slow periodic occurrence of spindle oscillations at $0.1 \mathrm{~Hz}$ was still present, as was the associated slow depolarization (Fig. 13B). However, after about 15-20 min, the whole picture had changed notably. First, during spindle oscillations the interburst frequencies always increased, passing from 7-8 $\mathrm{Hz}$ to about $13-14 \mathrm{~Hz}$. This was associated with a shortening of interburst repolarizing phases with no major change in the duration of individual depolarizing waves (compare traces $\mathrm{A}$ and B in Fig. 14). Second, in the quiescent periods between spindle sequences, another oscillation developed at a frequency of 4-5 Hz. This newly emerging rhythm can be seen in Figure 13 , where trace A shows the spontaneous activity preceding the spindle sequence of trace B. On a background of fast-rising depolarizations, rhythmic depolarizing waves crowned with spike bursts dominated the interspindle periods. When spindling occurred, a slow depolarization developed, and depolarizing waves shifted in frequency from $4-5 \mathrm{~Hz}$ to about $13-14 \mathrm{~Hz}$. The 4-5 $\mathrm{Hz}$ pattern then resumed for another 8-10 sec, and the whole sequence was repeated.

\section{Discussion}

On the basis of the evidence already mentioned in the introduction, it has been proposed that the RE nucleus was the pace-
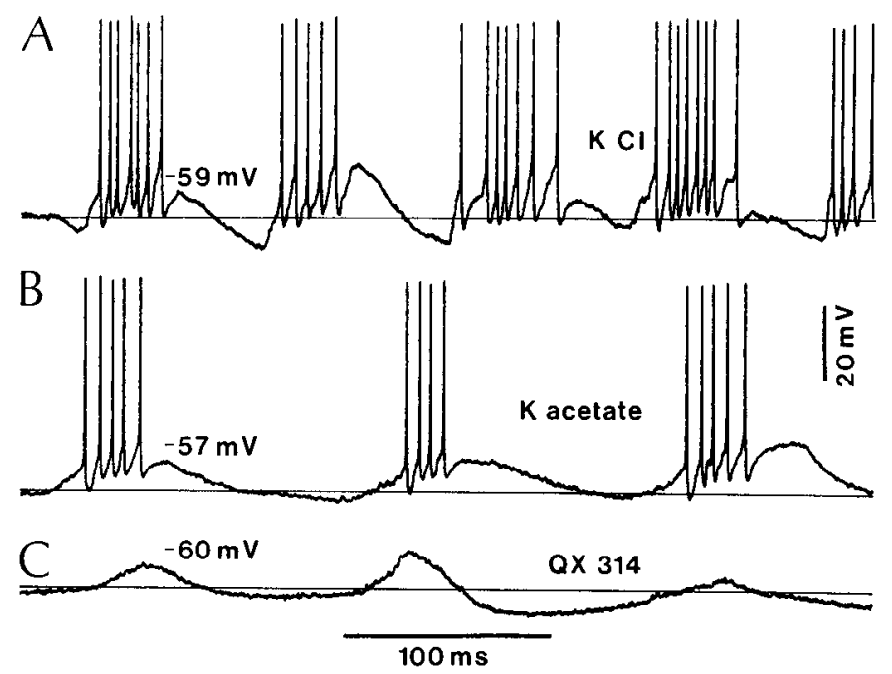

Figure 14. Modification of membrane potential trajectories during spindle sequences by $\mathrm{Cl}^{-}(A)$ and QX314 (C) injections. Control spindle sequence in $B$. Recordings obtained from 3 different RE neurons. 
maker of thalamic spindle oscillations. This conclusion is also supported by the present electrophysiological results.

\section{Identification of intrinsic currents}

RE neurons are endowed with a set of intrinsic membrane properties that by their nature do not distinguish them from other thalamic cells or from other types of cells in the CNS. What makes these cells different, however, is the location and relative predominance of their different conductances.

RE cell somatic action potentials are clearly $\mathrm{Na}^{+}$dependent given their abolition by QX314. However, spikes were not followed by prolonged AHPs as in other thalamic neurons. This could be due to masking of $\mathrm{Ca}^{2+}$-activated $\mathrm{K}^{+}$currents by inward currents or, more likely, to the absence of any sizable $\mathrm{Ca}^{2+}$ entry associated with somatic spike production. Spike repolarization and early undershoot might then be ascribed to activation of delayed rectifier $\mathrm{K}^{+}$currents, followed by activation of $I_{\mathrm{a}} \mathrm{K}^{+}$currents.

In addition to fast $\mathrm{Na}-\mathrm{K}$ conductances underlying somatic spike electrogenesis, RE cells possess 2 distinct inward currents that, in soma recordings, appear to have overlapping activation voltage. The first one is a noninactivating inward current that produced ramplike voltage trajectories preceding spike take-off. Activation of this conductance was voltage dependent and produced upswing deflections that led and lagged, respectively, the rising and falling components of a trapezoidal current pulse injected on a background of hyperpolarization. The ionic nature of this current is not yet known, but it is likely to be $\mathrm{Na}^{+}$ dependent, as in most of the nerve cells in which it has already been identified. The presence of a $\mathrm{Na}^{+}$-dependent persistent current in RE neurons is further suggested by the blockage of some components of spontaneous oscillations following intracellular injections of QX314. However, QX314 did not produce complete abolition of the progressive increase in membrane potential observed during current pulse injections. This could be the result of an incomplete blockage of persistent $\mathrm{Na}^{+}$currents by the drug, or it might also be ascribed to the activation of another, QX-resistant, slowly inactivating current of remote origin. Coactivation of slowly inactivating $\mathrm{Na}^{+}$and $\mathrm{Ca}^{+}$currents of different origin by somatic current pulses has already been described in Purkinje neurons (Llinás and Sugimori, 1980).

The second inward current is a QX314-resistant transient current deinactivated by hyperpolarization. Its activation produces burstlike firing. As in other thalamic neurons (Deschênes et al., 1984; Jahnsen and Llinás, 1984a, b), RE cells seem to possess a low-threshold $\mathrm{Ca}^{2+}$ conductance deinactivated by membrane hyperpolarization. However, RE cell LTRs were longer-lasting ( 75 vs $40 \mathrm{msec}$ ) and required larger somatic hyperpolarizations for their deinactivation $(20-30$ vs $5-10 \mathrm{mV})$. This leads us to conclude that RE cell LTRs have a dendritic origin. In this respect, RE neurons appear to be more similar to substantia nigra neurons than to other thalamic cells. Indeed, it has been shown in vitro that the former possess a dendritic LTR having duration and voltage-dependent characteristics similar to those observed in RE neurons (Llinás et al., 1984). The presumed dendritic location of this $\mathrm{Ca}^{2+}$ conductance would also explain the apparent overlap of its activation voltage with that of the proximal persistent $\mathrm{Na}^{+}$current. The production of rhythmic LTRs when RE cells recovered from hyperpolarization strongly supports their pacemaker role in thalamic oscillations. Possible mechanisms underlying this oscillatory behavior are still a matter of speculation. However, one attractive possibility would be that this sort of rhythmicity is generated through the interplay of dendrodendritic inhibitory interactions and the operation of the low-threshold $\mathrm{Ca}^{2+}$ conductance (see below).

Unless in our recording conditions RE cell dendrites were tonically hyperpolarized, the presence of dendritic LTRs would imply that dendrites possess active hyperpolarizing mechanisms for deinactivation of this $\mathrm{Ca}^{2+}$ conductance. In somatic recordings, no obvious short- or long-lasting hyperpolarizations resembling IPSPs were observed. This may be due to the distal location of hyperpolarizing events and/or to a passive distribution of the $\mathrm{Cl}^{-}$gradient across the cell membrane. Repolarizing potentials always developed slowly and smoothly. Hyperpolarizations that were not preceded by depolarizations were not observed. However, isolated hyperpolarizations or hyperpolarizations leading to rebound LTRs were recorded after QX314 injections (see Fig. 13C). They lasted for 50-100 msec and had small amplitudes (up to $5 \mathrm{mV}$ ). Given their small size, these hyperpolarizations would never be followed by LTRs if their origin were somatic. They ought to be produced in dendrites. Although we have no definitive indications about their nature, reasonable assumptions can be made. There surely exists a dendritic $\mathrm{Cl}^{-}$conductance of synaptic origin. This is suggested by the "disinhibitory" effect of intracellular $\mathrm{Cl}^{-}$injections and by the presence of dendrodendritic GABAergic synapses between RE cells (Deschênes et al., 1985; Yen et al., 1985). It is also very likely that $\mathrm{RE}$ cell dendrites possess a $\mathrm{Ca}^{2+}$-activated $\mathrm{K}^{+}$conductance. Indeed, this dendritic conductance has been demonstrated in almost all neuronal types studied up to now, and given the dendritic location of the low-threshold $\mathrm{Ca}^{2+}$ conductance, its presence in RE cell dendrites appears very likely.

\section{Mechanisms of $R E$ cell oscillations}

Field potential and unit recordings in the RE nucleus have shown that spindle sequences occurred simultaneously in pools of RE neurons even after their isolation from the rest of the thalamus (Steriade et al., 1986). Obviously there should exist a synchronizing mechanism within the RE nucleus itself. Neighbor RE cells fire and rest in phase during spindle sequences, and these sequences resume every $8-10 \mathrm{sec}$. The oscillatory behavior of RE cells is then characterized by 2 different rhythms, and each of these rhythms would require distinct and possibly interdependent synchronizing mechanisms.

Synchronization on a time scale of 8-10 sec cannot result from the operation of usual synaptic mechanisms which work on a time scale of milliseconds. However, it has been shown that RE neurons contained a somatostatin-like peptide (Graybiel and Elde, 1983), and it appears likely that this peptide might have a modulatory action on the slow oscillation. The ionic mechanisms of this oscillation are also poorly understood. The depolarizing component was blocked by QX314, suggesting that it was generated by the activation of a persistent $\mathrm{Na}^{+}$current. The ionic mechanism producing the slow hyperpolarizing phase could be similar to that activated by somatostatin in CA1 hippocampal neurons (Pittman and Siggins, 1981).

Individual waves of the faster $10 \mathrm{~Hz}$ oscillation were made of distinct components. The first component consists of a series of fast-rising potentials whose nature is still uncertain. They may represent unitary EPSPs resulting from burst discharges of thalamocortical neurons. This is suggested by their burst-type occurrence at frequencies similar to those of spike bursts in the latter cells. They may also represent high-threshold spikes generated in distal dendrites. However, these possibilities are not mutually exclusive since these fast potentials could be dendritic spikes driven by the synaptic impingement of thalamocortical axonal collaterals on RE cell dendrites. The second component, which lasts for about $70 \mathrm{msec}$, is probably a $\mathrm{Ca}^{2+}$ LTR of dendritic origin. This component was not abolished by injections of hyperpolarizing currents or QX314, and its time course was similar to that of LTRs produced by current pulse injections. The late hump that was blocked by QX314 and hyperpolarizing currents appears to be generated by a transient activation of the persistent $\mathrm{Na}^{+}$current by the preceding depolarization.

Repolarizations between bursts could correspond to active hyperpolarizations of dendritic origin, as observed after QX314 
injections. We propose that 2 hyperpolarizing mechanisms are involved: $\mathrm{Ca}^{2+}$-activated $\mathrm{K}^{+}$currents and $\mathrm{GABA}$-activated $\mathrm{Cl}^{-}$ currents. The $\mathrm{K}^{+}$conductance increase would be triggered by $\mathrm{Ca}^{2+}$ LTRs, and the IPSPs would result from the operation of dendrodendritic inhibitory synapses. These dendrodendritic interactions are thought to fulfill an important role in the synchronization of spindle oscillations. As in the case of the slow oscillation, there should exist another synchronizing mechanism that allows a pool of RE cells to fire in synchrony during spindles. Synchronization at $10 \mathrm{~Hz}$ could be achieved by a push-pull type of activity mediated by the interplay of dendrodendritic interactions and the operation of the low-threshold $\mathrm{Ca}^{2+}$ conductance. The sequence of events taking place during oscillations would then be the following in a given RE neuron (say, neuron A). (1) Dendritic hyperpolarization through dendrodendritic GABAergic synapses would deinactivate the low-threshold $\mathrm{Ca}^{2+}$ conductance in neuron $A$. (2) Upon return of the dendritic membrane potential of neuron $\mathrm{A}$ to its resting state, a $\mathrm{Ca}^{2+}$ spike would be triggered. (3) Calcium entry in neuron A dendrites will be followed by GABA exocytosis and hyperpolarization of other cells' dendrites postsynaptic to neuron A dendrites. (4) Hyperpolarization in the latter dendrites would then deinactivate the low-threshold $\mathrm{Ca}^{2+}$ conductance, and again hyperpolarization would result in other dendrites synaptically coupled in the network. In this way, oscillations could start at any point in the network and spread to adjacent cells.

\section{How important is the network?}

There is no question that synaptic interactions play a key role in the synchronization of RE cell oscillations. But could single RE cells oscillate? The answer is probably yes. In fact, they have the appropriate conductances to do so, and they do oscillate at their own rhythm during interspindle periods after intracellular $\mathrm{Cl}^{-}$injections. Strangely, these $4-5 \mathrm{~Hz}$ intrinsic oscillations are in the same frequency range as those of inferior olive neurons in vitro. The mechanism is probably similar in both cases, involving the interplay of $\mathrm{K}^{+}$and $\mathrm{Ca}^{2+}$ currents. However, it would be stretching the point to explain this auto-oscillatory behavior with data presently available.

The observation of rhythmic LTRs in response to hyperpolarizing current pulses after QX314 injections might also suggest an auto-oscillatory behavior. However, these oscillations could also result from the push-pull type synaptic interaction discussed previously. This last possibility appears likely since, under the same experimental conditions, intracellular current pulses never triggered oscillations in thalamocortical neurons, which nevertheless possess similar ionic conductances (unpublished observations).

The genesis of thalamic oscillations requires the participation of several intrinsic and synaptic mechanisms that are far from being completely understood. At this point, additional experimentation in vitro might lead to a better understanding of their role.

\section{References}

Andersen, P., and S. A. Andersson (1968) Physiological Basis of Alpha Rhythm, New York, Appleton-Century-Crofts.

Andersen, P., J. C. Eccles, and T. A. Sears (1964) The ventrobasal complex of the thalamus; types of cells, their responses and their functional organization. J. Physiol. (Lond.) 174: 370-399.

Andersen, P., S. A. Andersson, and T. Lomo (1967) Some factors involved in the thalamic control of spontaneous barbiturate spindles. J. Physiol. (Lond.) 192: 257-281.

Andersson, S. A., and J. R. Manson (1971) Rhythmic activity in the thalamus of the unanesthetized decorticate cat. Electroencephalogr. Clin. Neurophysiol. 31: 21-34.

Connor, J. A., and C. F. Stevens (1971) Voltage-clamp studies of a transient outward membrane current in gastropod neural somata. J. Physiol. (Lond.) 213: 21-30.

Dempsey, E. W., and R. S. Morison (1942) The interaction of certain spontaneous and induced cortical potentials. Am. J. Physiol. 135: 301-308.

Deschênes, M., A. Madariaga-Domich, and M. Steriade (1985) Dendrodendritic synapses in the cat reticularis thalami nucleus: A structural basis for thalamic spindle synchronization. Brain Res. 334: 165168.

Deschênes, M., M. Paradis, J. P. Roy, and M. Steriade (1984) Electrophysiology of neurons of lateral thalamic nuclei in cat: Resting properties and burst discharges. J. Neurophysiol. 51: 1196-1219.

Graybiel, A. M., and R. P. Elde (1983) Somatostatin-like immunoreactivity characterizes neurons of the nucleus reticularis thalami in the cat and monkey. J. Neurosci. 3: 1308-1321.

Jahnsen, H., and R. Llinás (1984a) Electrophysiological properties of guinea-pig thalamic neurones: An in vitro study. J. Physiol. (Lond.) 349: 205-226.

Jahnsen, H., and R. Llinás (1984b) Ionic basis of electroresponsiveness and oscillatory properties of guinea-pig thalamic neurones in vitro. J. Physiol. (Lond.) 349: 227-247.

Jasper, H. H. (1954) Functional properties of the thalamic reticular system. In Brain Mechanisms and Consciousness, F. Delofresnaye, ed., pp. 374-401, Blackwell, Oxford, UK.

Landry, P., and M. Deschênes (1981) Intracortical arborization and receptive fields of identified ventrobasal thalamocortical afferents to the primary somatic sensory cortex in the cat. J. Comp. Neurol. 199: 345-371.

Llinás, R., and M. Sugimori (1980) Electrophysiological properties of in vitro Purkinje cell somata in mammalian cerebellar slices. J. Physiol. (Lond.) 305: 171-195.

Llinás, R., and Y. Yarom (1981) Properties and distribution of ionic conductances generating electroresponsiveness of mammalian inferior olivary neurons in vitro. J. Physiol. (Lond.) 315: 569-584.

Llinás, R., S. A. Greenfield, and H. Jahnsen (1984) Electrophysiology of pars compacta cells in the in vitro substantia nigra-A possible mechanism for dendritic release. Brain Res. 294: 127-132.

Meech, R. W. (1978) Calcium-dependent potassium activation in nervous tissue. Annu. Rev. Biophys. Bioeng. 7: 1-18.

Morison, R. S., and D. L. Basset (1945) Electrical activity of the thalamus and basal ganglia in decorticate cats. J. Neurophysiol. 8: 399-414.

Pittman, Q. J., and G. R. Siggins (1981) Somatostatin hyperpolarizes pyramidal hippocampal neurons in vitro. Brain Res. 121: 402-408.

Puil, E., and P. L. Carlen (1984) Attenuation of glutamate-action, excitatory postsynaptic potentials, and spikes by intracellular QX222 in hippocampal neurons. Neuroscience 11: 389-398.

Roy, J. P., M. Clercq, M. Steriade, and M. Deschênes (1984) Electrophysiology of neurons of lateral thalamic nuclei in cat: Mechanisms of long-lasting hyperpolarizations. J. Neurophysiol. 51: 1220-1235.

Steriade, M., and M. Deschênes (1984) The thalamus as a neuronal oscillator. Brain Res. Rev. 8: 1-63.

Steriade, M., P. Wyzinski, and V. Apostol (1972) Corticofugal projections governing rhythmic activity. In Corticothalamic Projections and Sensorimotor Activities, T. Frigyesi, E. Rinvik, and M. Yahr, eds., pp. 221-272, Raven, New York.

Steriade, M., M. Deschênes, L. Domich, and C. Mulle (1985) Abolition of spindle oscillation in thalamic neurons disconnected from nucleus reticularis thalami. J. Neurophysiol. 54: 1473-1497.

Steriade, M., L. Domich, M. Deschênes, and G. Oakson (in press) The reticular thalamic nucleus: A pacemaker for EEG spindle rhythms. J. Neurophysiol.

Velasco, M., J. E. Skinner, K. D. Asaro, and D. B. Lindsley (1968) Thalamocortical systems regulating spindle bursts and recruiting responses. I. Effect of cortical ablations. Electroencephalogr. Clin. Neurophysiol. 25: 463-470.

Villablanca, J., and J. Schlag (1968) Cortical control of thalamic spindle waves. Exp. Neurol. 20: 432-442.

Yen, C. T., M. Conley, S. H. C. Hendry, and E. G. Jones (1985) The morphology of physiologically identified GABAergic neurons in the somatic sensory part of the thalamic reticular nucleus in the cat. $J$. Neurosci. 5: 2254-2268. 